\title{
Subjective motion and acceleration induced by the movement of the observer's entire visual field
}

\author{
S. C. P. WONG and B. J. FROST \\ Queen's University, Kingston, Ontario K7L 3N6, Canada
}

\begin{abstract}
Three experiments were carried out to trace the developmental time course of apparent subjective rotation induced by rotating a tall striped drum around an observer. In Experiment 1, rotation of the drum led to increasingly frequent reports of subjective rotation over the first $30 \mathrm{sec}$ of stimulation by the optokinetic stimulus, after which subjects experienced mostly apparent subjective rotation and a small amount of drum rotation. In Experiment 2, using a magnitude estimation technique to assess the speed of drum and subjective rotation, subjects reported subjective acceleration and drum deceleration of about the same magnitude over the first $30 \mathrm{sec}$ of the 1-min trial, followed by a steady level of subjective rotation with some residual drum movement. In Experiment 3, using three different drum speeds, it was found that the speed of steady-state rotation, as well as subjective acceleration and drum deceleration, are linear functions of the speed of the inducing stimulus. Implications of these observations towards the explanation of how we perceive a stable environment during locomotion are discussed.
\end{abstract}

Viewing a large stimulus pattern moving continuously in one direction, a stationary observer sometimes feels himself moving in the opposite direction while the pattern appears to be stationary. Illusions of this sort have long been documented (Helmholtz, 1911; Mach, 1906; Thalman, 1921) and even widely exploited for entertainment purposes in amusement parks (Wood, 1895) and more recently in circumambient film projection.

A convenient way to present such a stimulus is to have an observer sit in the center of a large cylinder, the patterned inside wall of which covers his entire visual field. Rotating the cylinder in one direction causes observers to feel that they are being rotated in the opposite direction while the cylinder may appear to stop moving. Psychophysical studies of this effect (circularvection) have been made by a number of investigators (Brandt, Dichgans, \& Koenig, 1973; Dichgans \& Brandt, 1972; Fischer \& Kornmüller, 1930; Young, Dichgans, Murphy, \& Brandt, 1973). Other types of subjective motion induced by visual stimulation have been produced either by moving a large visual pattern around the observer's line of sight (Dichgans, Held, Young, \& Brandt, 1972; Held, Dichgans, \& Bauer, 1975) or by the vertical or horizontal linear movement of large stimulus patterns over the observer's peripheral visual field (Berthoz, Pavard, \& Young, 1975; Johansson, 1977). These manipulations produced subjective tilt and apparent vertical and horizontal movements (linearvection) of the observer, respectively. Subjective rotation and lateral nystagmus have also been produced by the rotation of a sound field around the observer (Dodge, 1923; Lackner,
1977; Stein, 1910; Urbantschitsch, 1897) and by the passive rotation of the subject's horizontally extended arm about a vertical axis (Brandt, Büchele, \& Arnold, 1977). The former was termed audiokinetic and the latter arthrokinetic circularvection.

With a cylinder rotating at a constant speed around the observer, Brandt et al. (1973) and Dichgans and Brandt (1972) found that the sensation of subjective rotation so induced could not be distinguished from one induced by physically rotating the observer at the same speed but in the opposite direction inside the stationary cylinder. Subjective rotation developed gradually within 3 to $4 \mathrm{sec}$ after the trial began and reached a steady state of subjective rotation by about $10 \mathrm{sec}$, after which no apparent drum rotation was reported. It has also been shown that onset latency of subjective rotation is lengthened considerably if the inducing moving pattern is placed in front of a stationary pattern, but not vice versa (Brandt, Wist, \& Dichgans, 1975). During prolonged stimulation by a moving pattern, a decrease in velocity or even a periodic reversal of the direction of apparent motion may occur (Brandt, Dichgans \& Büchele, 1974). By using masks to present the same area of moving stripes at different eccentricities, it was found that the intensity of subjective rotation was much larger when the peripheral rather than "the central retina was stimulated. The strong sensation of orientational changes experienced in this illusion has led a number of investigators to postulate the convergence of visual motion information onto vestibular centers. Such visual-vestibular interactions have been demonstrated in electrophysiological experiments in which moving visual stimuli modulated firing 
of units in the vestibular nuclei of goldfish, cats, and monkeys. Moreover, the direction of the modulation (an increase or decrease in firing rate) was determined by the direction of movement of the visual stimulus (Allum, Graf, Dichgans, \& Schmidt, 1976; Daunton \& Thomsen, 1976; Dichgans, Schmidt, \& Graf, 1973; Henn, Young, \& Finley, 1974).

Of particular interest to this study is the period during which the illusion gradually develops to reach a steady state of subjective rotation. It is during this period that the brain has to deal with conflicting sensory information: visual information indicating the possible presence of position changes, whereas vestibular and kinaesthetic inputs indicate the contrary. A careful study of the events that take place within this period may shed some light on the question of how the brain integrates different sources of sensory information.

This study attempted to replicate and extend some of the above findings and to investigate in particular the developmental time course of subjective rotation.

\section{METHOD}

\section{Procedure}

Subjects sat inside a drum, $2 \mathrm{~m}$ tall and $1.5 \mathrm{~m}$ in diameter, the inside wall of which was lined with alternating vertical black and white stripes, each $4^{\circ}$ in width. The Michelson ratio of the stripes was $0.81(\mathrm{~L} \max -\mathrm{Lmin} / \mathrm{L} \max +\mathrm{Lmin})$. The drum could be rotated in a clockwise or counterclockwise direction at speeds that could be varied from a few deg/sec to about $180 \mathrm{deg} / \mathrm{sec}$. The velocity and direction of rotation were monitored throughout the experiment by connecting a circular microtorque potentiometer to the axle of the drum and recording voltage variations on a pen recorder. Even illumination inside the drum was provided by an incandescent light source located just above the subject's head. Extraneous noise was masked by white noise delivered through headphones which the subject wore throughout the experiment. Subjects sat on a chair which could be rotated smoothly through about $30^{\circ}$ clockwise or counterclockwise from a central position. A footrest attached to the chair prevented the subject from orienting himself through contact with the floor. However, subjects were never misled into believing that the chair could make complete rotations.

Thus seated with his head supported by a headrest, the subject's visual field was filled entirely by the wall of the drum. In the following experiments, subjects sat in the dark inside the drum which was then set into clockwise rotation. After the drum had reached a constant velocity, the inside light was turned on to signal the beginning of a trial. Light offset indicated the end of a trial, which was followed by a 1-min dark interval before the next trial began. No fixation point was provided in this series of experiments.

\section{Subjects}

The subjects were 12 male and 9 female unpaid university students between the ages of 18 and 28 .

\section{EXPERIMENT 1}

Experiment 1 was designed to replicate earlier findings that subjective rotation could be induced by the rotation of the observer's entire visual field and to trace the development of subjective rotation over a 1-min interval. With the drum rotating at $30 \mathrm{deg} / \mathrm{sec}$, the subjects were required to press one of three buttons throughout the 1-min trial to indicate whether they observed only the drum rotating, a combination of drum rotation and subjective rotation, or subjective rotation alone. The duration and temporal location of each press was recorded on a pen recorder. Each of eight subjects was given five 1-min trials.

\section{Results}

Figure 1 shows the percentage of trials subjects reported experiencing drum rotation or subjective rotation, or a combination of the two, at the end of every 5 -sec period throughout the 1 -min trial. At first, the subjects experienced mostly drum rotation or a combination of drum rotation and subjective rotation. The proportion of trials when only drum rotation was reported then decreased sharply until, after $25 \mathrm{sec}$, drum rotation alone was never reported (except by one subject for $2 \mathrm{sec}$ ). After about $30 \mathrm{sec}$ of stimulation, a steady state was reached during which subjective rotation was reported in about $75 \%$ of the trials. In the rest of the trials, subjects reported a combination of subjective and drum rotation. The direction of subjective rotation was, of course, opposite to the direction of drum rotation. Although there were considerable interindividual variations, remarkable consistencies occurred within the individual. Subjects interviewed after the experiment reported that the onset of subjective rotation was often followed by the gradual increase in the speed of subjective rotation together with the gradual decrease in drum speed.

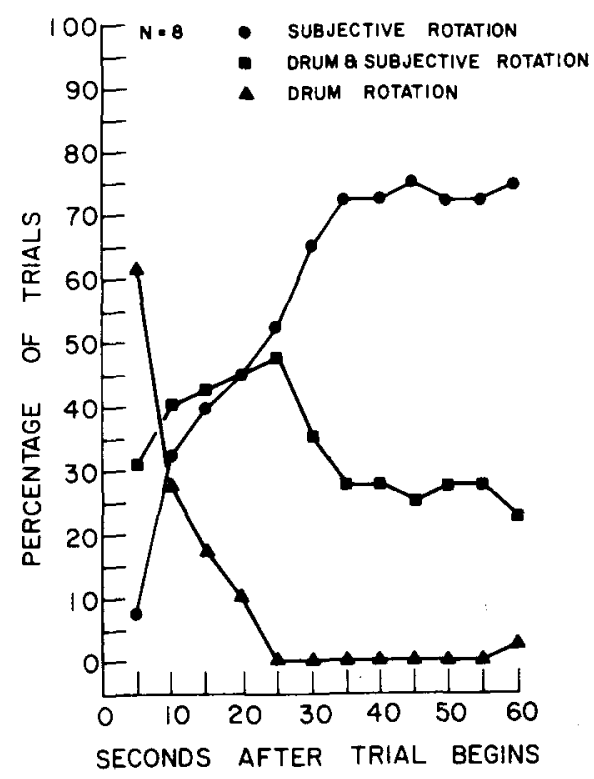

Figure 1. The percentage of trials subjects reported one of the three states of motion during a 1-min trial. 


\section{Discussion}

This experiment confirms recent observations by Brandt et al. (1973) and earlier reports (Fischer \& Kornmüller, 1930; Thalman, 1921) that rotation of an observer's entire visual field often leads to the report of apparent subjective rotation. However, in contrast to Brandt's report that subjective rotation reached a steady level about $10 \mathrm{sec}$ after trial onset, it was found that a steady state was reached after about $30 \mathrm{sec}$ of stimulation. These results, nevertheless, are in agreement with those of a related experiment in which apparent subjective tilt was induced by a large visual display rotating around the observer's line of sight (Held et al., 1975). Subjective tilt also reached asymptote about $30 \mathrm{sec}$ after rotation commenced. Also evident in this experiment is that, in some trials, subjects did not experience subjective rotation alone but a combination of drum and subjective rotation throughout the 1 -min trial.

These discrepancies between data reported by Brandt and ourselves could be accounted for, at least in part, by the difference in procedure. While our subjects indicated their perception of motion by button presses, allowing three alternative perceptual states to be recorded throughout a trial, the subjects in Brandt et al.'s experiment used a stopwatch to time the latency of both the initial onset of subjective rotation and the beginning of steady-state subjective rotation. A number of the present subjects, especially during the first $30 \mathrm{sec}$ of stimulation, fluctuated between experiencing subjective rotation and a combination of subjective and drum rotation. These fluctuations decreased as the trial progressed and is evident in the results as the gradual increase in the frequency that subjects reported only subjective rotation as opposed to reporting a combination of subjective and drum rotation. Brandt et al.'s (1973) latency measurements indicate the first instance that their subjects experienced only subjective rotation and, unless they made other measurements not mentioned in their report, they would have to assume that from then onwards subjects would continue to experience ony subjective rotation. This would account for the shorter latency of steady-state onset they reported and the fact that all their subjects appeared to reach a steady state of subjective rotation sometime during the trial.

The results of the present experiment indicate considerable fluctuations in the initial stages of each trial. However, reports of subjective rotation occurred with increasing frequency over the first $30 \mathrm{sec}$. Also of interest is the observation that there appeared to be subjective acceleration and drum deceleration during the early parts of the trial. This trade-off between subjective and objective velocity was investigated further in Experiment 2.

\section{EXPERIMENT 2}

In order to trace and quantify the change in the speed of subjective and drum rotation during a trial, subjects were instructed to give magnitude estimates (Stevens, 1957) of the apparent speed of the drum and also estimates of subjective rotations at 5 -sec intervals throughout the 1-min trial. Five seconds after light onset and every $5 \mathrm{sec}$ thereafter, a tone was sounded, immediately after which the subjects gave the two estimates. Shortly before the trial began, the rotating drum $(30 \mathrm{deg} / \mathrm{sec})$ was illuminated briefly $(1.5 \mathrm{sec})$ and the subjects were told to use that as the standard speed and to assign to it a number 10 . When the standard was presented, the exposure of the subject to the moving drum was too short to produce subjective rotation. Thus, the standard speed, represented by the number 10 , should be close to the physical speed of the drum. Each of the nine subjects tested in this experiment received five trials.

Based on the results from the last experiment, subjective acceleration and drum deceleration were measured by the slope of the linear regression line fitted to the portion of the function which extended from the 5th- to the 30th-sec mark.

\section{Results and Discussion}

Figure 2 shows the subjects' magnitude estimates

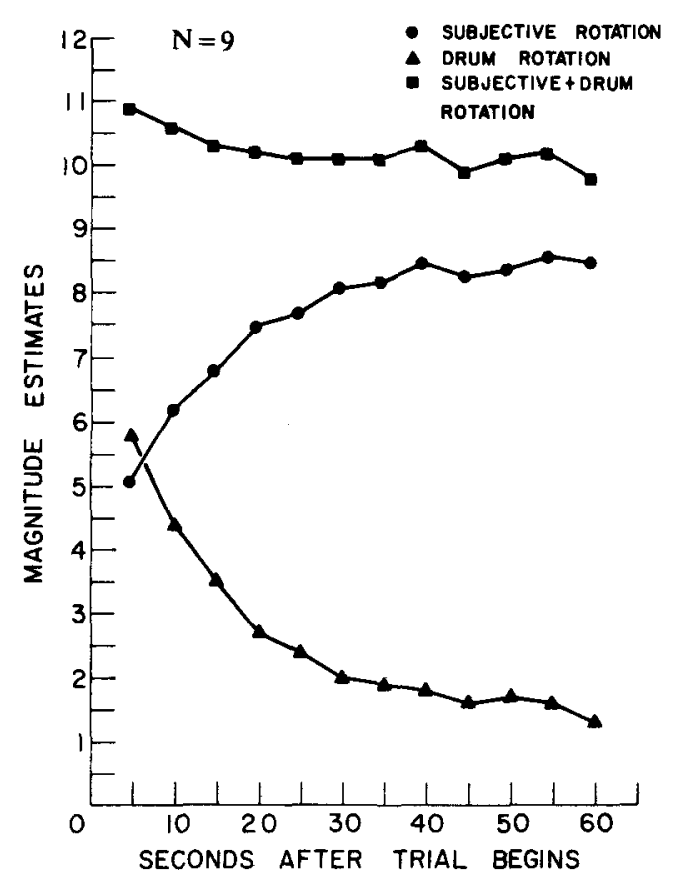

Figure 2. Magnitude estimates of subjective and drum speeds over a 1-min trial. 
of the speed of drum rotation and subjective rotation over the 1-min trials.

Significant changes of drum and subjective velocities occurred between the 5th and the 30th sec, $\mathrm{t}(8)=5.07, \mathrm{p}<.001 ; \mathrm{t}(8)=3.72, \mathrm{p}<.01$, respectively, but not in the following $30 \mathrm{sec}, \mathrm{F}(5,30)=.08$, $\mathrm{p}>.1 ; \mathrm{F}(5,30)=.05, \mathrm{p}>.1$, respectively. Subjective rotation accelerated rapidly at first, then more slowly, until it reached an asymptote at about $30 \mathrm{sec}$ after the trial began. Drum rotation showed a rapid deceleration initially, reaching a steady level about $30 \mathrm{sec}$ after trial onset. In short, as reported in the previous experiment, the change from experiencing mainly drum rotation to mainly subjective rotation occurred rapidly at first, then more slowly, and was completed about $30 \mathrm{sec}$ after the trial began. The magnitude of subjective acceleration (.12) and drum deceleration $(-.15)$ as measured by the respective slopes of the regression lines were very similar, suggesting that subjective acceleration and drum deceleration of about the same magnitude occurred before reaching a steady level of subjective rotation.

Furthermore, these functions describing the speed of subjective and drum rotation showed a very high negative correlation $(r=-.99)$ over the 1 -min trial. If the magnitude estimates of the speed of drum rotation and subjective rotation are summed at each of the 5-sec points, the sum comes close to 10 , which was the value assigned to the physical speed of the drum. This suggests that the amount of movement information, while remaining constant throughout the trial, was represented mostly by the physical movement of the drum at the beginning of the trial and was experienced later as a combination of drum and subjective rotation; the proportion of each was a function of the duration of exposure to the moving stimulus.

It might be argued that the deceleration of the drum which so closely matches the subjective acceleration could simply be a reflection of the way subjects were using the pairs of magnitude estimates (i.e., the tendency to use two numbers that summed to 10) rather than a reflection of the perceived motion. A conceptually similar experiment was performed in which a different group of subjects were required only to give estimates of either subjective or drum rotation on separate trials. The results were similar in every way to those obtained in Experiment 2.

\section{EXPERIMENT 3}

This experiment was designed to determine, first, if the functions that describe drum and subjective rotation would change with different drum speeds and, second, to confirm Brandt et al.'s (1973) observations that the speed of subjective rotation varied as a linear function of stimulus speed. The procedure was identical to the last experiment, except that drum speeds of 20,30, and $40 \mathrm{deg} / \mathrm{sec}$ were used. Each of four subjects was tested with all three drum speeds. Subjective accelerations and drum decelerations were measured by the slope of the linear regression line fitted to the portion of the function which extended from the 5th- to the 30th-sec mark. Steady-level subjective rotation for each of the three drum speeds was computed by taking the average of the magnitude estimates from the 35 th- to the 60 th-sec mark.

\section{Results and Discussion}

The results illustrated in Figure 3 show a similar pattern for each drum velocity; that is, the speed of subjective rotation increased to reach an asymptotic level while in about the same period of time the drum decelerated almost to a stop. The steady level of subjective rotation reached, as well as the magnitude of subjective acceleration and drum deceleration over the first $30 \mathrm{sec}$ of the trial, were linear functions of the stimulus speed. At any particular stimulus speed, the magnitudes of subjective acceleration and drum deceleration were quite similar (Table 1).

The results indicated that steady-state subjective rotation was always preceded by a period of apparent subjective acceleration and corresponding stimulus deceleration proportional to the speed of the inducing stimulus, and, in agreement with Brandt et al.'s (1973) observations, the speed of steady-state subjective rotation was a linear function of stimulus speed.

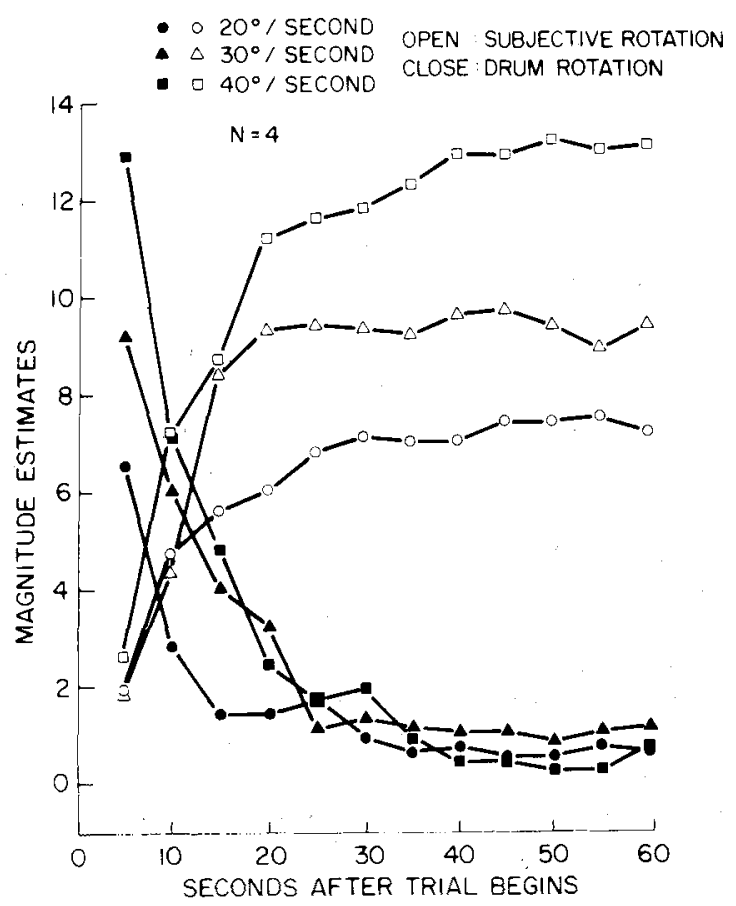

Figure 3. Magnitude estimates of subjective and drum speeds over a 1 -min trial at different stimulus speeds. 
Table 1

Magnitude of Subjective Acceleration and Drum Deceleration and the Speed of Steady-State Subjective Rotation (Magnitude Estimates) at Different Stimulus Speeds

\begin{tabular}{cccc}
$\begin{array}{c}\text { Drum } \\
\text { Speed* }\end{array}$ & $\begin{array}{c}\text { Subjective } \\
\text { Acceleration } \dagger\end{array}$ & $\begin{array}{c}\text { Drum } \\
\text { Deceleration } \dagger\end{array}$ & $\begin{array}{c}\text { Steady-State } \\
\text { Subjective } \\
\text { Speed }\end{array}$ \\
\hline 20 & .19 & -.18 & 7.3 \\
30 & .31 & -.31 & 9.4 \\
40 & .35 & -.42 & 12.9 \\
\hline
\end{tabular}

*Degrees per second. $\quad$ tSlope.

\section{GENERAL DISCUSSION}

Our results corroborate previous findings (Brandt et al., 1973; Fisher \& Kornmüller, 1930; Held et al., 1975 , among others) that visual motion information has a powerful influence on spatial orientation: rotation of the observer's entire visual field leads to the perception of subjective rotation. In the present experiments, we have also found that, after being exposed to a full-field motion for about $30 \mathrm{sec}$, subjects reached a steady perceptual state mainly consisting of subjective rotation but with a small residual stimulus motion. Visual motion information, while remaining constant throughout the trial, was experienced either as object motion or as apparent subjective motion, the proportion of each being dependent on the duration of exposure to the inducing stimulus. Steady-state rotation was always preceded by a period of subjective acceleration and drum deceleration of about the same magnitude. However, the final speed of subjective rotation reached and the magnitude of subjective acceleration and drum deceleration in the first $30 \mathrm{sec}$ are linear functions of the stimulus speed.

It is not surprising to find that the final speed of subjective rotation is a linear function of stimulus speed. When moving at uniform velocity, visual input is the major source of sensory information that allows the observer to judge how fast he is moving. However, it is of interest to note that a period of subjective acceleration took place when there was no corroborating vestibular, kinaesthetic, or visual input. The acceleration was not due to the slow phase of optokinetic nystagmus catching up with the moving stripes, as similar sorts of functions were found when subjects were asked to fixate on a stationary spot while observing the rotating drum.

A possible explanation is that, under normal circumstances, uniform subjective movement is invariably preceded by a short period of acceleration signaled by the vestibular and the visual systems. In the absence of the appropriate vestibular and visual input to indicate acceleration, visual signals generated by uniform velocity movement of the stimulus may nonetheless activate the necessary mechanisms to produce apparent acceleration, the magnitude of which is proportional to the velocity of the inducing stimulus.

Although for a short period of time, notably at the beginning of a trial, subjects could perceive stimulus motion, the visual system is strongly biased towards the perception of subjective motion when the entire visual field or large parts of peripheral visual areas are stimulated by moving stimuli. This phenomenon may reflect the operation of a visual mechanism responsible in part for distinguishing image motion produced by movements of the observer from that produced by object motion. Retinal image motion occurs during eye movements and locomotion but the visual world appears to be stationary. Helmholtz (1911) suggested that, during eye movements, visual stability is achieved by corollary signals from motor centers that cancel out retinal image motion. However, during locomotion, movement of the retinal image may occur in the absence of any corollary signal-e.g., while being artificially propelled straight ahead at a constant velocity. Nevertheless, the visual world still appears to be stationary.

An important difference between an object-induced and observer-induced image motion is that the former generally involves movement in small parts of the visual field whereas the latter often involves movement of the observer's entire visual field. Therefore, movement of one's entire retinal image, especially the peripheral visual image, could serve as a signal to the nervous system that the observer rather than the world is moving. However, for many subjects in the present experiments, stabilization of their visual field is not complete, especially during the beginning of a trial. This could be the result of the absence of vestibular information which, together with visual information, normally signals a period of acceleration before the occurrence of movement at a uniform velocity. Some indirect evidence supports this hypothesis. Brandt, Dichgans, and Büchele (1974) have shown that with discontinuous stimulation of the observer by an optokinetic stimulus (5-sec periods of stimulation alternating with 5-sec dark intervals), the latency of subjective rotation during the stimulation intervals over the first few cycles was shortened significantly due, presumably, to the positive aftereffect that was present during the dark interval. It has also been shown that a direction-specific reduction in latency of subjective rotation occurred in patients with a vestibular tonus imbalance due to an acute unilateral labyrinthine lesion (Hökendorf, Bles, \& Brandt, 1977). Other experiments are in progress to test this hypothesis further. 


\section{REFERENCES}

Allum, J. H. J., Graf, W., Dichgans, J., \& Schmidt, C. L. Visual-vestibular interactions in the vestibular nuclei of the gold tish. Experimental Brain Research, 1976, 26, 463-485.

Berthoz, A., Pavard, B., \& Young, L. R. Perception of linear horizontal self-motion induced by peripheral vision (linearvection). Experimental Brain Research, 1975, 23, 471-489.

Brandt, Th., Büchele, W., \& ARnold, F. Arthrokinetic nystagmus and ego-motion sensation. Experimental Brain Research, 1977, 30, 331-338.

Brandt, Th., Dichgans, J., \& Büchele, W. Motion habituation: Inverted self-motion perception and optokinetic after-nystagmus. Experimental Brain Research, 1974, 21, 337-352.

Brandt, Th., Dichgans, J., \& Koenig, E. Differential effects of central versus peripheral vision on egocentric and exocentric motion perception. Experimental Brain Research, 1973, 16. 476-491.

Brandt, Th., Wist, E. R., \& Dichgans, J. Foreground and background in dynamic spatial otientation. Perception \& Psychophysics, 1975, 17, 497-503.

Daunton, N. G., \& Thomsen, D. Otolith-visual interactions in single units of cat vestibular nuclei. Neuroscience Abstracts, 1976, 2. 1526.

Dichgans, J.. \& Brandt, Th. Visual-vestibular interactions and motion perception. In J. Dichgans \& E. Bizzi (Eds.), Cerebral control of eye movements and motion perception. Basel-New York: Karger, 1972.

Dichgans, J., Held, R., Young, L., \& Brandt, Th. Moving visual scenes influence the apparent direction of gravity. Science, 1972, 178, 1217-1219.

Dichgans, J.. Schmidt, C. L., \& GRaf, W. Visual input improves the speedometer function of the vestibular nuclei in the gold fish. Experimental Brain Research, 1973, 18, 319-322.

DODGE, R. Thresholds of rotation. Journal of Experimental Psychology, 1923, 6, 471-489.

Fischer, M. H., \& Kornmüller, A. E. Optokinetisch ausgelöste Bewegungswahrnehmungen und optokinetischer Nystagmus. Journal für Psychologie und Neurologie (Leipzig),1930, 41, 273-308.
Held. E., Dichgans. J., \& Bauer. J. Characteristics of moving visual scenes influencing spatial orientation. Vision Research, $1975,15,357-365$.

HELMHOLTz, H. von. [Helmholtz's treatise on physiological optics] (Translation edited by J. P. C. Southall). New York: Dover, 1962 (originally published 1909-1911).

Henn, V., Young, L. R., \& Finley, C. Vestibular nucieus units in alert monkeys are also influenced by moving visual fields. Brain Research, 1974, 71, 144-149.

Hökendorf, H., Bles, W., \& Brandt, Th. Direction specific reduction of circularvection latencies as a measure of latent labyrinthine vertigo. Pflügers Archiv Supplement, 1977, 368. R45, 179.

Johansson, G. Studies on visual perception of locomotion. Perception, 1977, 6. 365-376.

LACKNER, J. R. Induction of illusory self-rotation and nystagmus by a rotating sound-field. Aviation, Space and Environmental Medicine, 1977, 48, 129-131.

МACH, E. [The analysis of sensation] (Translation based on the 5 th ed. by S. Waterlow). New York: Dover. 1959 (originally published 1886; 5th ed. published, 1906).

STEIN, S. Von. Schwindel (Audiokinesis externa et interna). Leipzig: Lessier, 1910.

Stevens, S. S. On the psychophysical law. Psychological Review. 1957, 64, 153-181.

Thalman, W. A. The aftereffect of seen movement when the whole visual field is filled by a moving stimulus. American Journal of Psychology, 1921, 32, 429-441.

URBantschitsch, V. Über Störungen des Gleichgewichtes und Scheinbewegungen. Zeitschrift für Ohrenheilkunde, 1897, 31. 234-294.

Woon, R. W. The "haunted-swing" illusion. Psychological Review, 1895, 2, 277-278.

Young, L., Dichgans, J., Murphy, R., \& Brandt, Th. Interaction of optokinetic and vestibular stimuli in motion perception. Acta Oto-laryngoiogica, $1 \overline{9} \bar{\jmath}, \overline{7}, \overline{6} . \overline{2} 4-\overline{3} \mathbf{i}$.

(Received for publication December 8, 1977; revision accepted May 26. 1978.) 